\title{
¿Qué es la libertad?: un análisis de la modernidad al comunitarismo.
}

What is liberty?: an analysis from modernity until communitarianism.

DOI: 10.32870/sincronia.axxv.n79.8a21

\author{
Ignacio García Solano \\ Universidad de Guadalajara (MÉXICO) \\ CE: Ignaciogarciasolano@gmail.com / ID ORCID: 0000-0002-4358-5198
}

Esta obra está bajo una Licencia Creative Commons Atribución-NoComercial 4.0 Internacional

Recibido: 30/09/2020

Revisado: 03/11/2020

Aprobado: $17 / 11 / 2020$

\section{RESUMEN}

¿Cuáles son las interpretaciones sobre la idea de libertad que se presentan en las actuales discusiones dentro de la filosofía política? Este concepto, siendo demasiado vago, pretende delimitarse en las tres propuestas más relevantes dentro de los debates filosóficos y políticos en la actualidad. Dos de ellos son dados a través de la modernidad, los cuales pueden ser subdivididos en universales, quienes se basan en leyes prohibitivas y, en segundo lugar, individuales, quienes se basan en la selección de leyes permisivas. El tercer aporte es dado por los comunitaristas, quienes comienzan a hablar sobre la necesidad de una libertad de la pluralidad.

No es un objetivo tomar posición alguna sobre estas propuestas, por tanto, defenderlas es algo que definitivamente quedará omitido. El objetivo realmente planteado es únicamente presentar las discusiones que existen en torno a estas tres interpretaciones sobre libertad, sosteniendo por tesis que, todas ellas pasan a ser una aporía en cuanto a las ventajas y desventajas que generan siendo, por tanto, falibles. Además, conciliar todas esas propuestas es difícil, pues sus objetivos parten de lados opuestos que, al tratar de hacerlo se volverían contraproducentes.

El trabajo se presenta en tres secciones. La primera parte, se dedica a explicar la delimitación del tema que se plantea para luego pasar a los temas particulares. La segunda parte, dedica un espacio al análisis sobre las dos principales interpretaciones de la idea de libertad dadas en la modernidad. Por último, se presenta una alternativa a este concepto moderno de libertad, uno plural dado desde el pensamiento comunitario. 
Palabras Clave: Libertad. Universalismo. Individualismo. Pluralismo.

\section{ABSTRACT}

What are the interpretations of the idea of liberty that are presented in the current discussions within political philosophy? This concept, being too vague, tries to delimit itself in the three most relevant proposals within current philosophical and political debates. Two of them are given through modernity, which can be subdivided into universals, which are based on prohibitive laws and, secondly, individual, who are based on the selection of permissive laws. The third contribution is given by the communitarians, who begin to speak about the need for a liberty of plurality.

It is not an objective to take any position on these proposals, therefore, defending them is something that will definitely be omitted. The objective really raised is only to present the discussions that exist around these three interpretations on liberty, arguing by thesis that, all of them become an aporia in terms of the advantages and disadvantages that theyself generate, being, therefore, fallible. Also, reconciling all these proposals is difficult, since their objectives start from opposite sides that, in trying to do so, would become counterproductive.

The work is presented in three sections. The first part is dedicated to explaining the delimitation of the issue that arises and then moving on to the particular issues. The second part dedicates a space to the analysis of the two main interpretations of the idea of liberty given in modernity. Finally, an alternative to this modern concept of liberty is presented, a plural one given from community thought.

Keywords: Liberty. Universalism. Individualism. Pluralism.

\section{1. ¿Qué es la libertad?}

Hablar sobre libertad como tal, generaría un gran problema por su ambigüedad, pues este concepto puede comprenderse en diferentes aspectos. Uno de ellos es, cuando se habla de libertad como una capacidad motriz que permite a los hombres actuar bajo su propia convicción. También se puede discutir la existencia de libertad desde los aspectos deterministas, quienes se preguntan si realmente todos los hombres son libres de actuar o están determinados por ciertas causalidades que prescriben nuestras acciones. Quizá si seguimos revisando encontraremos muchos sentidos 
más para dicha concepción, sin embargo, la discusión que aquí interesa es hablar sobre la libertad política.

Esta temática, también dentro de la filosofía política, ha sido retomada varias veces y todas comprendidas nuevamente en diversos sentidos, por ello, el concepto debe ser todavía más acotado, ya que ha sido trabajado desde la antigua Grecia hasta la actualidad, teniendo por resultado una enorme cantidad de respuestas. Siendo así, se ha decidido partir desde el problema conceptual retomado en la modernidad. Algunos podrán decir que la modernidad también dio diferentes respuestas por cada autor que escribió sobre el tema, sin embargo, aquí me ha sido posible sintetizarlo en dos panoramas distintos, aquellos quienes buscan una libertad universal y quienes buscan una libertad individual. Lo mismo sucederá con la concepción dada desde el comunitarismo, teniendo por cada autor diversas respuestas, no obstante, también ha sido posible sintetizarla en una libertad de la pluralidad.

Antes de pasar a las definiciones particularizadas del concepto libertad, es menester definir otros conceptos secundarios que aquí van surgiendo. Por "modernidad" se deberá comprender como, aquel periodo histórico donde la razón comienza a ser un medio para justificar las creencias del hombre, haciendo una ruptura con un periodo anticuado o tradicional, donde sus creencias se encontraban basadas en la magia o el mito: "Aquí se encuentran los procesos que conllevan, por ejemplo, el comercio y el consumo, la razón y la ciencia, la industria y la tecnología, el Estado-nación y el sujeto-ciudadano, esferas públicas y espacios privados, religiones secularizadas y conocimientos desencantados". (Dube, 2009, p. 179).

Por "razón" o "racionalidad" compréndase aquella capacidad del hombre para planificar acciones que sean un medio para obtener ciertos fines esperados:

Actúa con racionalidad que considera la acción como dirigida a conseguir un resultado [...] quien dirige su acción hacia un fin, hacia unos medios y hacia las consecuencias colaterales, ponderando racionalmente los medios en relación con los fines, los fines en relación con las consecuencias colaterales y, por último, los distintos fines posibles entre sí. (Weber, 2005, p. 103). 
Aquí se han retomado tres ideas sobre el concepto de libertad, dos versiones sentadas en la modernidad y una en el comunitarismo, porque hasta la actualidad son las más destacadas en los debates filosóficos o políticos. Además, todos ellos, han buscado planificar una teoría de la "justicia", pues consideran que una sociedad ordenada justamente será aquella sociedad que permitirá el mayor grado de libertad posible para todos los hombres.

\section{La libertad en la modernidad}

Los inicios de las discusiones sobre la idea de libertad política moderna comenzaban a tomar relevancia durante el periodo ilustrado, cuando los filósofos discutían otras formas de gobierno opuestas al monarquismo absolutista. Estas monarquías se elegían por dos derechos. Primeramente, el ius divino, donde algún hombre era elegido por designio de Dios para ser gobernante entre el resto de los hombres: “Dios, pues, es el autor y dispensador de la felicidad, es quien distribuye los reinos terrenos tanto a buenos como a malos, puesto que Él es el solo Dios verdadero". (Agustín, 2007, p. 190). A este derecho le acompañaba otro llamado ius naturalismo, al cual, recurriendo a la política de Aristóteles, se afirmaba que toda persona nacía para obedecer o nacía para mandar, pero no nacían con ambas cualidades, o eran esclavos o eran amos: "En efecto, el que es capaz de prever con la mente es un jefe por naturaleza y un señor natural, y el que puede con su cuerpo realizar estas cosas es el súbdito y esclavo por naturaleza [...]". (Aristóteles, 1988, p. 47). Siendo así, los monarcas tenían la creencia de poseer una procedencia divina y dotes naturales que los convertían en los legítimos gobernantes del reino.

Para el filósofo inglés John Locke, debía ser la razón del hombre la que gobernara al Estado, no las creencias divinas o naturalistas, y aunque él también habla sobre el "derecho natural", éste ha cambiado su sentido. El ius naturalismo son aquellos derechos inalienables con los que nace todo hombre, como derecho a la propiedad privada, a la libre elección, a la libre expresión o a la vida. Las monarquías serán análogamente un gobierno paternalista, donde todo hombre inmaduro debe ser cuidado por el padre, por lo cual, debe someterse a su ley. Locke objetará diciendo que, 
todos los hombres, por el simple hecho de nacer racionales, poseen una capacidad (o un derecho natural) de elección, entonces cada quien puede ser libre de elegir lo que él desee. De tal modo, para el Estado liberal, los hombres capaces de razonar, son capaces de emanciparse, de gobernar sus propias vidas. (Locke, 2004).

A este modelo liberal se le uniría una herramienta útil para la política moderna que llegaría a desplazar a los gobiernos absolutistas, sería el contractualismo. Según los contractualistas, el Estado no debería ser manejado por una persona, sino que, por voto mayoritario, los ciudadanos de determinado Estado deberían ser capaces de elegir racionalmente bajo qué gobierno o bajo qué leyes deberían estar regidos. Dependiendo de si viviesen bajo una democracia representativa (donde la ciudadanía selecciona a un representante) o participativa (donde los ciudadanos deben seleccionar su propia legislación). Nicola Matteucci lo define de la siguiente manera: “[...] un acuerdo tácito o expreso entre varios individuos, acuerdo que significaría el fin de un Estado de naturaleza y el inicio del Estado social y político". (Matteucci, 2015, p. 351). A este proyecto contractual se le puede conocer también como democracia.

La democracia, según Alexis de Tocqueville, daría inicio en los Estados Unidos de América, donde los padres fundadores, inspirados en la ilustración europea y americana, iniciarían el primer modelo liberal que, ni la misma Europa, hasta ese momento, había logrado conseguir. (Tocqueville, 1984). Los grupos de puritanos ingleses, quienes buscaban un lugar para tener libertad religiosa, decidieron partir a la colonización de Norteamérica, siendo apodados como "peregrinos". Una vez asentados, fundaron en Massachussets una de las primeras colonias inglesas en el Nuevo Mundo, donde comenzaron a dedicarse al campo y al comercio. Estados Unidos fundado por diversas religiones protestantes que escapaban de las restricciones de Roma, el papado y el catolicismo, inculcaron a sus generaciones el ideal de libertad que, tras su guerra por la independencia, lograrían formar la primera constitución democrática del mundo. (Tocqueville, 1984).

Muchos intelectuales escribieron sobre este proyecto contractualista, no obstante, son dos los aquí pertinentes por mencionar. El primero sería el filósofo suizo Jean Jacques Rousseau, el segundo el pensador inglés John Locke. En este punto la libertad moderna se quebrantaría en dos 
modelos. Uno propondría la selección de leyes universales donde a todo ciudadano se le rigiera de forma igualitaria. En el otro se elegirían leyes particulares para que cada individuo fuese capaz de tomar sus propias decisiones.

\section{1 libertad universal}

A este primer grupo de liberales he decidido llamarlos "universalistas", pues pretenden generar un Estado con un contrato social, donde la libertad se rige mediante la elección libre del ciudadano para la selección directa de leyes bajo las cuales, al ser seleccionadas por voto mayoritario, deberán ser usadas para gobernar a todos los hombres por igual. Les llamo "universalistas" justamente por esa misma idea. La ley funcionará para todos en general sin excepciones, además, partirá de la idea de que todo hombre es igual y, por ende, no debe haber una ley que sea injusta si fue seleccionada por la mayoría. Incluso, algunos llegan a aceptar la desigualdad de los hombres, pero, parten de que es la mayoría quien decide qué es lo mejor para ellos y los demás. Aun así, no deja de ser un modelo liberal, ya que la legislación siempre es tomada bajo decisiones libres y de forma electoral.

Este modelo contractual tendría sus bases en el pensamiento de Rousseau, quien propondría desde el Discurso Sobre los Orígenes de la Desigualdad Entre los Hombres (1983), que esto comenzaba cuando se creía que el hombre tenía derecho individual de apropiarse de cuanto él quisiera, olvidando que la tierra no es de nadie sino de todos:

El primer hombre a quien, cercando un terreno, se lo ocurrió decir esto es mío y halló gentes bastante simples para creerle fue el verdadero fundador de la sociedad civil. ¡Cuántos crímenes, guerras, asesinatos; cuántas miserias y horrores habría evitado al género humano aquel que hubiese gritado a sus semejantes, arrancando las estacas de la cerca o cubriendo el foso: «iGuardaos de escuchar a este impostor; estáis perdidos si olvidáis que los frutos son de todosy la tierra de nadie!». (Rousseau, 1983, p. 30).

Su teoría democrática, a la cual se le puede atribuir los orígenes de la democracia participativa, redactada en el Contrato Social (2014), partía de la idea en la que todos los ciudadanos de 
determinada población, deberían reunirse para realizar un contrato, donde todos estarían de acuerdo en lo pactado y ni una sola persona se opondría a ello. Mientras alguien se opusiera el contrato debería reiniciarse, pues entonces sería un contrato injusto, pues por lo menos para uno, generaría desigualdad y limitaría su libertad. Ello ayudaría a crear una serie de leyes con una justicia perfecta, pues nadie votaría jamás por una ley que le pusiese en desventaja. No obstante, estas legislaciones serían generales, es decir universales, para todos ya que nadie podría estar exento a ellas. Aunque el voto es particular y racionalizado, los acuerdos siempre serán generales, nadie puede obligar a otro para elegir un voto, pero sí es posible llegar a acuerdos donde todos queden satisfechos y he allí la libre elección:

Por la misma razón que la soberanía es inalienable, es indivisible, pues la voluntad es general o no lo es; es la del cuerpo del pueblo o solamente la de una parte. En el primer caso, esa voluntad declarada es un acto de soberanía y hace ley. En el segundo, no es más que una voluntad particular, o un acto de magistratura; es a lo sumo, un decreto. (Rousseau, 2014, p. 278).

A este grupo de pensadores universalistas se le podría unir el filósofo alemán Immanuel Kant. En su obra Hacia la Paz Perpetua (2014) denominaría a este modelo democrático como "republicanismo". No obstante, a diferencia de Rousseau, para Kant, la legislación no sería realizada por el voto mayoritario del pueblo, pues donde manda la mayoría, mandan muchos sobre algunos, irrumpiendo a la autonomía de estos pocos. El voto universal de los ciudadanos sólo garantizaría la representación del soberano quien seleccionaría la legislación adecuada para cumplir una voluntad general. Por ende, el gobierno representativo es, quien debería legislar la voluntad no de uno, sino de todos. Incluso, la minoría de soberanos que gobiernan al Estado es una mayor garantía para esta voluntad general, pues son menos soberanos los que disputarán leyes opuestas que se opongan a una generalización. Kant, al igual que Rousseau, también apuestan a la igualdad de las personas y, por ende, concluyen que todos deben ser gobernados bajo las mismas leyes sin distinciones ni excepciones: 
[...] la democracia es, en el sentido genuino de la palabra, necesariamente un despotismo, porque funda un poder ejecutivo donde todos deciden sobre y, en todo caso, también contra uno (quien, por tanto, no da su consentimiento), con lo que todos, sin ser todos, deciden; esto es una contradicción de la voluntad general consigo misma y con la libertad.

Toda forma de gobierno que no sea representativa es en realidad una no-forma, porque el legislador no puede ser al mismo tiempo ejecutor de su voluntad en una y la misma persona [...]. Se puede decir, por consiguiente, que cuánto más reducido es el número de personas del poder estatal (el número de soberanos) y cuanto mayor es la representación de los mismos, tanto más abierta esta la constitución a la posibilidad del republicanismo [...]. Al modo de gobierno que es conforme a la idea del derecho pertenece el sistema representativo, único en el que es posible un modo de gobierno republicano y sin el cual el gobierno es despótico y violento [...]. (Kant, 2014, pp. 313-314).

Otra escuela filosófica que también puede unirse a este grupo de liberales universalistas es la utilitarista. Jeremy Bentham, a quien se le atribuye como fundador de este pensamiento filosófico e inspirado en la escuela de Epicuro, definía como "utilidad" a todo aquello que fuese capaz de generar la felicidad de los hombres, pero, además, la felicidad buscada por el utilitarismo no sería la felicidad particular, sino la felicidad general:

La felicidad pública es el objeto del legislador, cuya ciencia consiste en conocer el bien del pueblo y hallar los medios de realizarlo, debiendo seguirse al efecto la invariable regla de la utilidad general, que es el principio del raciocinio en la legislación. (Bentham, 1839, p. 1).

Bentham, era consciente de que una ley podría representar un mal para algunas personas, pues no todas se beneficiarían de ella. Además, nadie es igual para sentir placer con la misma acción y disminuir su grado de dolor, ya que eso genera la felicidad, por ende, la ley no debía ser pensada para erradicar todo mal sino para erradicar un mal mayor al mal que debería causar: 
Toda ley es un mal, porque toda ley es una infracción de la libertad. Así, pues, para dar una ley, es preciso asegurarse antes de que lo que se quiere evitar es realmente un mal, y que este mal es mayor que el mal de la ley. (Bentham, 1839, p. 26).

Por ende, es posible inferir, que mientras este mal afecte a una mayoría, una minoría afectada debería someterse bajo esa misma ley, pues sería la ley más útil que se podría lograr.

John Stuart Mill, otro utilitarista que definirá placer en el mismo sentido que su mentor Jeremy Bentham: "Por felicidad se entiende el placer y la ausencia de dolor; por infelicidad el dolor y la falta de placer". (Mill, 2014, p. 60). También reconocerá el principio de mayor placer donde hay placeres más útiles que otros. Pero cómo establecer cuál placer es más valioso se preguntaría el autor, a lo que responderá afirmando que, el mayor placer es aquel preferido por la mayoría: “De entre dos placeres, si hay uno al que todos, o casi todos los que han experimentado ambos, conceden una decidida preferencia, independientemente de todo sentimiento de obligación moral para preferirlo, ése es el placer más deseable". (Mill, 2014, pp. 63-64). Por tanto, se puede reformular que el concepto de utilidad para él es, el mayor placer para la mayor cantidad de personas posibles. Siendo, por tanto, la mejor ley, aquella que beneficie a una mayoría y, todos deberán ser regidos por ella.

Ahora bien, alguien podría preguntarse: “¿qué tipo de leyes serían universales?”. Para responder a ello, decido Ilamarlas "leyes prohibitivas". Esta clasificación de leyes, son aquellas que aplican tanto a quienes desean seguir dicho modelo legislativo, pero también afectan a quienes desean tener una elección libremente diferente. En la actualidad existen, y es de conocimiento general, grupos políticos conservadores (asociados a las corrientes políticas derechistas) quienes buscan legislar leyes que penalicen cualquier decisión respecto a los derechos políticos individuales y que, por libertad, cada quien debería tener derecho a decidir. Por ejemplo, la penalización del aborto, el uso de narcóticos, el matrimonio igualitario, entre otros. Estas leyes no permiten la libertad individual del sujeto, sino que garantizan que al ser todos iguales entonces deben omitir que cada persona tenga deseos o necesidades diferentes al resto; oh bien, deben aceptar una 
voluntad mayoritaria siendo sometidos a ella involuntariamente y, he allí lo problemático en este modelo liberal.

Quizá la prohibición en el utilitarismo sea un poco confusa, pues siempre busca la mayor felicidad para el mayor número de personas, pero; la prohibición sigue presente. Para explicarlo mejor pongo dos ejemplos. Imagínese una sociedad conformada por un grupo mayoritario $\mathrm{Y}$ y un grupo minoritario $\mathrm{X}$, donde $\mathrm{Y}$ se beneficiaría con la desaparición de $\mathrm{X}$, entonces $\mathrm{Y}$ tendría el derecho permitido para desaparecer a X, ya sea exiliándolo o matándolo, por lo cual $\mathrm{X}$ tendría prohibido radicar dentro de esa sociedad o tendría prohibido vivir. Ahora supóngase que la legalización de las drogas blandas causa placer a la mayoría de los ciudadanos, no obstante, un grupo minoritario de personas comienzan a tener problemas por el uso de dichos narcóticos y los familiares deciden que ellos deberían dejar de consumirlos, pero, tendrían prohibido evitarlo pues, para esas personas, a pesar de sus problemas de adicción, son un problema menor frente al problema mayor en caso de prohibir la droga, por tanto, el derecho de elección para que a alguien se le prohíban los narcóticos sería considerado nulo.

\section{2 libertad individual}

El individualismo sería la visión liberal donde cada sujeto es libre de tomar sus propias decisiones, más esta libertad debe estar limitada hasta donde da inicio la libertad de otro más. Aquí podría mencionarse el trabajo de John Locke, el Segundo Tratado Sobre el Gobierno Civil (2004), escritos para defender la democracia y contrarrestar al absolutismo de su época, mediante la propuesta de otro tipo de contrato social. El autor da inicio a este escrito mencionando que el estado máximo de naturaleza para los hombres es el estado de perfecta libertad: "[...] para que cada uno ordene sus acciones y disponga de posesiones y personas como juzgue oportuno, dentro de los límites de la ley de la naturaleza, sin pedir permiso ni depender de la voluntad de ningún otro hombre". (Locke, 2004 , p. 36). Aunque define que todos por naturaleza poseen una igualdad sobre su derecho de libertad, pone los límites mediante lo que menciona como "ley natural": "[...] ninguno debe dañar a otro en lo que atañe a su vida, salud, libertad o posesiones". (Locke, 2004, p. 38). 
Otro derecho natural del hombre es, dice Locke, la adquisición de una propiedad privada, pues ello es básico para la conservación del hombre, por tanto, además de natural es un derecho racional: "[...] una vez que nacen, los hombres tienen derecho a su autoconservación y, en consecuencia, a comer, a beber, y a beneficiarse de todas aquellas cosas que la naturaleza procura para su subsistencia [...]". (Locke, 2004, p. 55). No obstante, consideraba que ningún hombre estaba interesado en trabajar más de lo que podía conservar, por ende, los límites de sus adquisiciones estarían limitadas naturalmente a los límites de su capacidad laboral, entonces, ningún hombre podría tener derecho, aunque así lo quisiera, a obtener demasiado, pues sus mismas capacidades lo limitarían y, por ley natural, no tendrían el derecho de invadir lo ajeno: "La parcela que un hombre labraba para sí mismo era claramente visible; y era inútil y deshonesto que labrase demasiado terreno o que tomara más de lo que le servía para satisfacer sus necesidades". (Locke, 2004, p. 75).

Ahora bien, Locke no caería en la ingenuidad de creer que una sociedad se podría componer absolutamente de sujetos totalmente individuales, no obstante, la formación de una sociedad civil no afectaría la individualidad de cada persona. Los hombres al nacer naturalmente libres están igualmente amenazados por estos extremos de libertad, corriendo el riesgo de ser atacados por alguien más, por ello los individuos deben socializarse abandonando esa condición natural en la convivencia con más personas:

Esto lleva a querer abandonar una condición en la que, aunque él es libre, tienen lugar miedos y peligros constantes; por lo tanto, no sin razón está deseoso de unirse en una sociedad con otros que ya están unidos o que tienen intención de estarlo con el fin de preservar sus vidas, sus libertades y sus posesiones, es decir, todo eso a lo que doy el nombre genérico de "propiedad". (Locke, 2004, p. 134).

Y aunque bien considera Locke, que el "derecho natural" es algo inalienable, también es consciente de que debe haber una ley de penalización para quien abuse y quiera llegar más allá de sus límites de libertad generando daño a otras personas. Por tanto, los hombres deben asociarse con la intención de crear un contrato social, abandonando el estado natural para formar al Estado. Pero 
éste, no debe privar de la libertad permitida a los hombres, sino que debe garantizarla. Siendo así, las únicas leyes escogidas deberán ser aquellas que garanticen los derechos individuales penalizando a quienes dañen a otros individuos, teniendo una serie de leyes que sólo deben dedicarse a resguardar la libertad y asegurar la vigilancia en bien de su prospera conservación:

Así, el Estado se origina mediante un poder que establece cuál es el castigo que corresponde a las diferentes transgresiones de aquellos que, entre los miembros de una sociedad, piensan que merece la pena cometerlas; este es el poder de hacer leyes, y a él debe añadirse el poder de castigar cualquier daño que se le haga a un miembro de la sociedad, cometido por alguien que no pertenece a ella. (Locke, 2004, p. 103).

Este movimiento individualista comenzaría a ser muy conveniente para los sistemas económicos que comenzaban a desarrollarse durante la revolución industrial, el capitalismo, que sería el desarrollo de la economía política, siendo a partir de entonces difícil separar una u otra práctica. Uno de los aportes clásicos realizados a este sistema es el propuesto por el filósofo y economista escocés Adam Smith. Centrado en las cuestiones éticas, escribiría un libro titulado La Teoría de los Sentimientos Morales (1978), que sería a futuro una base pilar para sus teorías económicas. Para él, al igual que Locke, las relaciones sociales surgen en la necesidad de convivir unos hombres con otros por el bien de la supervivencia humana, no obstante, este sentimiento de supervivencia, comenta el autor, es un acto de egoísmo, pues cada hombre busca su propio beneficio, curiosamente, para conseguirlo debe hacerlo con ayuda de alguien más, por lo cual, para obtener ayuda de otra persona, éste debe estar dispuesta a también beneficiar a ese otro sujeto, siendo entonces un beneficio recíproco:

[...] la sociedad se convierte en una necesidad para él, y cuanto propenda al sostén y bienestar sociales, es considerado como cosa que remotamente fomenta su propio interés; por lo contrario, todo aquello que amenaza con perturbar o destruir la sociedad, lo considera en cierta medida dañino y pernicioso a sí mismo. (Smith, 1978, p. 139). 
La obra más importante de Smith es sin duda La Riqueza de las Naciones (1995), en la cual, el autor se dedica a describir las funciones del sistema económico inglés en su tiempo. La idea de una economía libre, dice el autor, es generar la capacidad de cada hombre, para que éste pueda conseguir sus propios ingresos y con ello pagar sus propios servicios y no sea el Estado quien deba tener que brindárselos: "[...] que el pueblo pueda conseguir ese ingreso o esa subsistencia por sí mismo [...]". (Smith, 1995, p. 539). Una vez que el Estado es capaz de proporcionar estas capacidades a los ciudadanos, ellos deben adquirir individualmente bajo el trabajo, la capacidad necesaria para subsistir con sus propios medios. Aquí es donde entra en función su teoría moral, en una breve metáfora que se le ha conocido como la teoría de la "mano invisible", donde el beneficio de una persona en la adquisición de riquezas termina por beneficiar a toda una sociedad, logrando la fluidez de la moneda para que ésta llegue a cualquier otra mano:

En la medida en que todo individuo procura en lo posible invertir su capital en la actividad nacional y orientar esa actividad para que su producción alcance el máximo valor, todo individuo necesariamente trabaja para hacer que el ingreso anual de la sociedad sea el máximo posible. Es verdad que por regla general él ni intenta promover el interés general ni sabe en qué medida lo está promoviendo. Al preferir dedicarse a la actividad nacional más que a la extranjera él sólo persigue su propia seguridad; $y$ al orientar esa actividad de manera de producir un valor máximo él busca sólo su propio beneficio, pero en este caso como en otros una mano invisible lo conduce a promover un objetivo que no entraba en sus propósitos. El que sea así no es necesariamente malo para la sociedad. Al perseguir su propio interés frecuentemente fomentará el de la sociedad mucho más eficazmente que si de hecho intentase fomentarlo. Nunca he visto muchas cosas buenas hechas por los que pretende actuar en bien del pueblo. (Smith, 1995, p. 554).

Más recientemente con Friedrich Hayek se reforzarían las tesis de Locke y Smith con otra formulación del individualismo, fundando un sistema de economía política que sigue vigente hasta la fecha, llamado por algunos el "neoliberalismo". Al igual que sus predecesores intelectuales, admitirá la necesidad de la relación de los sujetos individuales en la sociedad, afirmando que estas 
prácticas personales no pretenden quebrantar la vida social, sino al contrario, ésta debe ser necesaria para garantizar las libertades individuales. También comprenderá que, al ser toda persona diferente al resto debe ser necesario para cada uno la lucha personal por sus propios intereses y necesidades, lo único igual para todos los hombres debe ser solamente la garantía de su libertad, una vez otorgado este derecho, cada quien deberá con su propia labor ser capaz de generar su propia subsistencia:

Here I may perhaps mention that only because men are in fact unequal can we treat them equally. If all men were completely equal in their gifts and inclinations, we should have to treat them differently in order to achieve any sort of social organization. Fortunately, the $y$ are not equal; and it is only owing to this that the differentiation of functions need not be determined by the arbitrary decision of some organizing will but that, after creating formal equality of the rules applying in the same manner to all, we can leave each individual to find his own level.

[Aquí puedo sin embargo menciona que sólo porque los hombres son de hecho desiguales podemos tratarlos equitativamente. Si todos los hombres fuéramos equitativamente iguales en sus habilidades e inclinaciones, tendríamos que tratarlos diferente en orden hacía algunos ciertos objetivos de organización social. Afortunadamente, ellos no son iguales: y es sólo debido a esto que la diferentes funciones necesitan no ser determinadas por decisiones arbitrarias de algún organismo social, sino que, cree formas iguales de las reglas aplicadas en la misma manera para que todos puedan individualmente buscar su propio lugar]. (Hayek, 1948, pp. 15-16).

Es importante conocer las diferencias que Hayek hace entre los conceptos de "liberty" y "liberties". La idea "liberty" es comúnmente usada en la lengua inglesa como una libertad universal, donde a todos se les trata por igual y todos son gobernados bajo el mismo sentido de libertad, en cambio la idea de "liberties" es usada en la misma lengua, para referirse a las libertades individuales que poseen todos los hombres para desarrollarse individualmente del resto: 
But while the uses of liberty are many, liberty is one. Liberties appear only when liberty is lacking: they are the special privileges and exemptions that groups and individuals may acquire while the rest are more or less unfree. Historically, the path to liberty has led through the achievement of particular liberties. But that one should be allowed to do specifi c things is not liberty, though it may be called "a liberty"; and while liberty is compatible with not being allowed to do specifi c things, it does not exist if one needs permission for most of what one can do. The difference between liberty and liberties is that which exists between a condition in which all is permitted that is not prohibited by general rules and one in which all is prohibited that is not explicitly permitted.

[Mientras el uso de libertad es variado, libertad es una. Las libertades aparecen cuando falta libertad: son los privilegios especiales y exenciones que grupos e individuos pueden adquirir mientras el resto son más o menos libres. Históricamente, el camino hacia la libertad ha conducido a través del logro de las libertades. Pero que a uno se le deba permitir hacer cosas específicas no es libertad, aunque pueda llamársele libertad; y aunque la libertad es compatible con no poder hacer cosas específicas, no existe si se necesita permiso para la mayoría de lo que se puede hacer. La diferencia entre libertad y libertades es la que existe entre una condición en la que todo está permitido sino está prohibido por reglas generales y una en la que está prohibido todo lo que no está explícitamente permitido]. (Hayek, 1960, p. 70).

Para conseguir este tipo de libertades individuales he decidido determinar que las leyes seleccionadas para este modelo político y económico deben basarse en aquellas que llamo "permisivas". Las "leyes permisivas" son aquellas que dejan al individuo a su libre elección el qué acción tomar. Diferentes a las leyes universales que aplican para ambos tipos de sujeto, quienes desean realizar una acción o quienes no la desean, éstas permiten al individuo tener un criterio para tomar esa decisión. Es decir, son aquellas que permiten el aborto, el consumo de drogas blandas, los matrimonios igualitarios, etc. Quien desee abortar, casarse con alguien del mismo género o consumir ciertos narcóticos es libre de hacerlo, como también es libre de negarse si esa no es su 
decisión. Obviamente, dichas leyes siempre tendrán sus limitaciones, pues hay cosas que no deben quedar al criterio del sujeto individual y que de hacerlas debe tomarse medidas requeridas para castigar y reprimir al individuo, como el asesinato, la violación, el robo, entre otros derechos que pondrían el riesgo la libertad y las garantías individuales de otros. Aquí queda marcada una gran diferencia entre la libertad individual y la universal propuesta por el utilitarismo, donde incluso si estos actos penalizados causan placer al sujeto, este no podrá realizarlos por el simple hecho de irrumpir en el derecho natural de alguien más, es decir el derecho a la vida o a la conservación de su integridad. No obstante, por más acertada que parezca esta versión de libertad no quedará infalible, siendo una de las interpretaciones más cuestionadas por los comunitaristas.

\section{La libertad para el comunitarismo: un concepto sobre la pluralidad}

El comunitarismo discutirá justo con los dos modelos liberales presentados en la filosofía de la "modernidad", tanto a los universalistas como a los individualistas, pues los considerará modelos excluyentes. Uno de los problemas básicos a discutirle será aquella idea sobre que todos los individuos deben ser iguales y tratados como tal, no obstante, los individualistas ya habían analizado esta objeción, pero para el comunitarismo, el individualismo también será igualmente otro modelo de exclusión social, e inconsistente, preocupándose por buscar una comunidad basada en ideas de pluralidad social. Es importante mencionar, que el comunitarismo, pese a sus críticas realizadas a la libertad moderna, no descartará todas sus propuestas, pero si encontrará varias inconsistencias con las cuales discutirá.

Para el filósofo Michael Walzer existen tres graves errores del liberalismo: la razón, la política y la pasión. El concepto de racionalidad afirmaría que todo hombre es libre y capaz de tomar sus propias decisiones y esa es una de las grandes mentiras del liberalismo, pues todos los hombres se encuentran determinados por un ambiente social regido por reglas y aunque éste, es libre de salirse para elegir otro ambiente, lo máximo que logrará conseguir es cambiar su entorno social por otro igualmente dominado por esas mismas reglas, por tal motivo, no hay un solo sujeto que pueda ser totalmente libre, sino solamente libre de elegir un entorno diferente: “¿Podríamos 
imaginarnos individuos que no tuvieran vinculaciones de ningún tipo? ¿lndividuos que no estuvieran determinados por la clase, la religión o el género, sino que carecieran de identidad y fueran completamente libres?". (Walzer, 2004, p. 35). Por ende, Walzer comprende que la libertad absoluta o individual no es posible, todas las personas carecen de una identidad o un logos propio, ya que estos son puestos por la misma sociedad donde cada sujeto se ha ido desarrollando a lo largo de su vida, sin embargo, no descarta una pequeña libertad, cuando alguien quien viva en una sociedad de forma involuntaria, pueda cambiarla:

[...] Nos movemos en dirección a la libertad cuando permitimos que alguien se salga: que se divorcie, se convierta a otra religión, se retire, pase a la oposición, o denuncie un contrato, etc. Nos movemos en dirección a la libertad cuando abrimos caminos para el cambio social en las asociaciones involuntarias y para la reordenación del estatus entre las asociaciones involuntarias. (Walzer, 2004, pp. 39-40).

En cuanto a la democracia representativa, para Walzer, hay un riesgo ocasionado en el proselitismo, que los partidos políticos tengan como único interés ganar las elecciones, aquí nuevamente se genera una especie de separación social en pequeños grupos que deben apoyar, con base a ciertas ideologías adquiridas en su entorno, a uno u otro bando. No obstante, la sociedad pasa a ser un medio no libre, pues se encuentra en uso para llegar a ciertos fines que beneficiarán ampliamente al partido ganador:

El camino democrático a la victoria implica que las personas se formen políticamente, se organicen y movilicen [...] siempre contra algo. El 'plus' es lo que legitima la victoria, y aunque la legitimidad se vea favorecida cuando se aportan buenos argumentos para cuestiones sustanciales, la victoria rara vez alcanza buenos argumentos. (Walzer, 2004, p. $61)$.

Pero, él tampoco logra encontrar una solución en la democracia participativa, puesto que éstas a pesar de tratar de incluir más al sujeto en las decisiones políticas, la organización entre una gran cantidad de personas implicadas en una sociedad simplemente no es posible: "No quiero decir con 
ello que los hombres y mujeres corrientes no posean la capacidad de argumentar racionalmente; sino, simplemente, que 100 millones de personas, o un millón o, sólo 100.000, no pueden 'discutir conjuntamente' [...]". (Walzer, 2004, p. 69).

Su última crítica sobre la pasión, radica en lo impulsivo que pueden ser las personas cuando éstas se dejan convencer por el discurso pasional que los políticos suelen ofrecer, actuando entonces en varias ocasiones de manera irracional: "La política suele tener que ver con personas que reúnen las dos cosas, las convicciones y las pasiones, la razón y el entusiasmo, en una sola relación inestable". (Walzer, 2004, pp. 83-84). Viéndolo de ese modo, la pasión y el proselitismo son dos ideas que se encuentran ligadas, ambas en lugar de guiarse por un argumento racional, prefieren despertar ciertas pasiones que liberen la irracionalidad de los hombres ocasionando un impulsivo acto social.

Su propuesta política será basada en un concepto llamado "justicia compleja", una forma de redistribución de los bienes sociales, no en un sentido tradicionalmente liberal, donde cada quien hace por sí mismo sus propias adquisiciones, sino de forma equitativa según las necesidades no sólo del sujeto y su entorno, sino de las necesidades sociales mismas basadas en sus diversos contextos que les fuerzan a tener diferentes soluciones a diversos problemas. He allí donde inicia la propuesta plural del comunitarismo. Un sujeto en silla de ruedas tendrá diferentes necesidades a alguien que pueda hacer un buen uso de sus piernas, este segundo sujeto no requerirá una casa habilitada para que la silla pueda pasar por cualquier lugar, pues así mismo sucede con las sociedades. Sociedades encontradas en diferentes medios climáticos no podrán cultivar los mismos alimentos. Si la sociedad fuese considerada igual, como si a los hombres se les considerase iguales, se le exigiría al hombre en silla de ruedas subir caminando por las escaleras de cualquier casa como a cualquier persona sana, al igual, a cualquier país se le entregaría una distribución igualitaria de semillas para sembrar sin tomar en consideración si el medio ambiente del lugar al que pertenecen lo permite o no:

La igualdad simple es una condición distributiva simple, de modo que si yo tengo 14 sombreros y otra persona tiene también 14, estamos en condición de igualdad. Y tanto mejor 
si los sombreros son predominantes, ya que entonces nuestra igualdad se extenderá a través de todas las esferas de la vida social. Desde la posición que asumo aquí, sin embargo, sólo tendremos el mismo número de sombreros, y es poco probable que los sombreros sean predominantes por mucho tiempo. La igualdad es una compleja relación de personas regulada por los bienes que hacemos, compartimos e intercambiamos entre nosotros; no es una identidad de posesiones. Requiere entonces una diversidad de criterios distributivos que reflejen la diversidad de los bienes sociales. (Walzer, 1997, p. 31).

Walzer hablará también de una política del reconocimiento, donde a cada hombre se le reconocerá por sus diferencias, es decir una política de la inclusión. No obstante, el reconocimiento de dichas diversidades no implicará la individualidad del sujeto, pues no se busca la autonomía fuera de la sociedad misma, sino que cada quien sea aceptado como es dentro de un grupo social, en el cual, nadie busque ser superior o dominar sobre los demás:

El ciudadano que se respete es un individuo autónomo. No quiero decir autónomo en el mundo, pues no sé qué implicaría eso. Es autónomo en su comunidad, un agente libre y responsable, un miembro participativo. Lo imagino como el sujeto ideal de la teoría de la justicia. Está en casa aquí, y conoce su lugar, "reina en su propia [compañía], no en otra parte", y no "desea poder sobre el mundo entero". Es todo lo opuesto al tirano, quien utiliza su noble cuna, su riqueza material o su cargo, incluso su celebridad, para reclamar bienes que no ha ganado y respecto de los cuales no tiene derecho alguno. (Walzer, 1997, p. 290).

En cuanto a la filosofía comunitaria de Taylor, partirá por una crítica al individualismo que él ha decido Ilamar como "atomismo". Una analogía en la cual, una sociedad ordenada por átomos, les permite a éstos actuar autónoma y desinteresadamente del resto: "Con frecuencia este atomismo se hace visible a través de un alegato en favor de lo que se denomina 'individualismo metodológico', el cual nos conmina a tratar las colectividades como compuestas por individuos". (Taylor, 1997, p. 178). Para objetar esta postura realizará un breve análisis sobre la conformación de la lengua, ya que ésta depende del entorno donde el sujeto se desarrolla. Si bien, todos los hombres 
poseemos ideas individuales, la única forma en que estas pueden ser expresadas es mediante la intersubjetividad, la relación subjetiva de un sujeto con otro, dada a través de la lengua, medio con el cual es posible expresar esas ideas internas que cada quien posee. Además, las ideas internas que cada quien tiene respecto al mundo no se quedan intactas mediante la comunicación lingüística con otras personas, sino que siempre va complementándose, por lo cual, aquí se encuentra un posicionamiento también gnoseológico, pues el conocimiento de cada persona depende de su relación no solamente personal con el mundo, también de su relación con alguien más. De igual manera, la lengua siempre se encontrará en diversos cambios constantes dependiendo de la cultura donde ésta se encuentre desarrollándose, por lo que ni el mismo lenguaje es inamovible cuando se hay relaciones humanas: "[...] un lenguaje es creado y sostenido en los continuos intercambios que tienen lugar en una determinada comunidad lingüística. Esta es su locus y esto es lo que, en última instancia, excluye al individualismo metodológico". (Taylor, 1997, p. 183).

Así como sucede con la lengua o con el conocimiento, sucede igualmente con las comunidades. Toda comunidad se conforma por relaciones sociales, pero sólo logra sostenerse cuando los integrantes de esta sociedad logran subsistir unos con otros, logrando esto únicamente buscando el bienestar común. En una comunidad las personas necesitarán tanto del carnicero, como el carnicero del campesino y el campesino del comerciante:

Las compresiones comunes no se pueden descomprendery ello se debe, como acabo de decir, al hecho de que es esencial para ser lo que son que no sean sólo para mí o para ti, sino para nosotros. Que nosotros poseamos una comprensión común presupone que hemos formado una unidad, un 'nosotros' que comprende conjuntamente y que por definición no se puede descomprender analíticamente. Si lo fuera, la comprensión no sería genuinamente común. Una relación de amistad es un ejemplo de una de las que descansan en una comprensión común y, por tanto, no es susceptible de un análisis atomista. (Taylor, 1997, p. 189).

Taylor verá un riesgo en las sociedades multiculturales, ya que ellas han dividido nuevamente a las sociedades, tal y como sucede con el individualismo, en pequeños fragmentos sociales, cada uno 
con una identidad personal separada del resto: indígenas con indígenas, feministas con feministas, homosexuales con homosexuales, etc. "Y en la exigencia aparece en primer plano, de muchas maneras, en la política actual, formulada en nombres de grupos minoritarios o 'subalternos'”. (Taylor, 2009, p. 53). No es que Taylor tenga algo en contra de la diversidad cultural, sino que solamente encuentra peligroso que estas sociedades divididas en diversas identidades trabajen de forma aislada al resto de una comunidad en lugar de trabajar todos ellos en común, sin necesidad de perder esa identidad. La comunidad no debe olvidar que cada identidad dada, ya sea personal como hablar de mi propia identidad, o una identidad social como yo perteneciendo a un cierto grupo, ésta siempre se otorga socialmente y no de forma aislada. Cuando una persona forja su propia forma de ser lo hace dentro de su convivencia con alguien más, al igual cuando decide pertenecer siempre a un grupo, lo hace tras socializar con dicha agrupación. Así como sucede con el lenguaje cuando se desarrolla mediante un determinado entorno cultural, lo mismo sucede con la identidad: "[...] el que yo descubra mi propia identidad no significa que la haya elaborado en el aislamiento, sino que la he negociado por medio del diálogo [...], con los demás". (Taylor, 2009, p. 65).

Taylor tampoco confrontará del todo al liberalismo clásico, pero no verá viable un Estado regido por una democracia representativa, aunque sí verá viabilidad en una participativa, diferenciándose aquí de Walzer. Para Taylor, ésta no sólo permitirá al sujeto involucrarse más en las decisiones y necesidades de la sociedad, también permitirá un respeto mayor a la diversidad cultural, teniendo en ello, una propuesta guiada hacia la pluralidad:

La libertad se entendía como una libertad ciudadana, la libertad del participante activo en los asuntos públicos. El ciudadano era 'libre' en el sentido de tener voz y voto en las decisiones del dominio político, el cual conforma la vida de cada uno. En la medida en que el autogobierno participativo es en sí mismo realizado habitualmente a través de acciones comunes, quizás es normal verlo como auténticamente animado por identificaciones comunes. Ya que ejercemos la libertad en acciones comunes, puede parecer natural que la valoremos como un bien común. (Taylor, 1997, p. 253). 
El riesgo que Taylor encuentra en un liberalismo individualista es la fragmentación de los sujetos en objetivos particulares olvidando tener también objetivos comunes. Él cree que un sistema federativo es una buena alternativa para regresar el poder democrático a la sociedad y limitar los poderes políticos del gobierno. Ello es una forma de lograr una sociedad subsidiaria:

Lo que puede contribuir a mitigar está sensación es la descentralización del poder, tal como observó Tocqueville. Y de este modo, en general, la devolución o la división de poderes, como en los sistemas federales, especialmente en los que se basan en el principio de subsidiaridad, puede ser buena para recobrar el poder democrático. Tanto más si las unidades a las que se les devuelve ese poder figuran ya como comunidades en las vidas de quienes las componen. (Taylor, 1994, p. 144).

Llegando a este punto es importante mencionar qué tipo de leyes serían adecuadas para un Estado (o una comunidad) conformada por el pensamiento comunitario. La única alternativa sería una serie de "leyes relativas" que permitan a cada diversidad cultural gobernarse bajo sus propios estándares sociales, pero sin aislarse del resto. ¿Quiénes son los pensadores de la modernidad para establecer un modelo ideal a cualquier cultura? ¿Cómo pueden justificar que su valor moral sea mejor que otro valor moral? El comunitarismo, por ende, debe buscar una comunidad centrada en dos aspectos pluriculturales, la alteridad y la solidaridad, reconocer las diferencias del “otro" y aun así trabajar en comunidad.

Es conocido que en todo el mundo y en su historia, han existido y aún existen culturas que pueden parecer extrañas a quienes se han desenvuelto en un mundo regido dentro del pensamiento moderno. No obstante, estas diversidades culturales demuestran que el mundo no es solamente de una única moralidad, sino que puede haber diversas moralidades, de las cuales difícilmente se podrá argumentar que alguna de ellas es mejor que otra, pues toda sociedad actúa siempre bajo la creencia de estar haciendo lo mejor para ella misma. El filósofo James Rachels quien ha trabajado el relativismo cultural menciona: 
No puede decirse de estas costumbres que son 'correctas' o 'incorrectas' pues esto implica que nosotros tenemos un criterio independiente de corrección o incorrección con el que pueden ser juzgadas. Pero no ha tal criterio independiente; cada criterio está ligado a una cultura. (Rachels, 2006, p. 41).

Pero, el mismo autor encontrará ciertas deficiencias en estas argumentaciones, pues las consecuencias podrían ser negativas, por ejemplo, nadie podría criticar otras prácticas culturales tan solo por ser diferentes a las propias, de ser así, entonces nadie podría criticar la exterminación de los judíos por tener una percepción diferente que debe ser respetada pues se violentaría el pensamiento de los nazis:

No condenar estas prácticas no parece progresista; al contrario, la esclavitud y el antisemitismo parecen incorrectos donde quiera que ocurran. Sin embargo, si tomamos en serio el relativismo cultural, tendremos que ver estás prácticas sociales como inmunes a la crítica". (Rachels, 2006, p. 46).

\section{Conclusión}

El problema generado por una libertad basada en la creencia de que todos son iguales, es justamente creer que a todas las personas se les debe tratar por igual, sin considerar qué necesidades o deseos diferentes al del resto pueda tener cada sujeto. A este problema se le buscó una alternativa dándole a las personas un derecho individual de elección, donde cada quien pudiera escoger lo que él desea según sus propios intereses y sin tener que depender de qué opinan los demás. No obstante, la lucha individual de cada quien, conllevó a una supervivencia del más apto al medio ambiente social, sin importar las desventajas que otra persona pudiera tener, o la asimetría de libertad generada, donde algunos tendrían la oportunidad de gozar de más libertad que otros, por ejemplo, quienes nacieran en una familia económicamente mejor posicionada al del resto. Por otro lado, los comunitaristas quienes buscarían una libertad basada en la pluralidad, es decir, la alteridad y colectividad, recaen en el problema de la relativización. Generar realidades diversas donde todas deben ser respetadas por el simple hecho de ser diferentes al resto, ocasionaría que 
toda objeción a cierto estilo de vida o a cierta cultura fuese considerada como violenta, pues según este relativismo, buscaría reprimir otros pensamientos, sin importar que estos mismos pongan en riesgo la libertad o la vida de otras personas, por ejemplo, no se podría objetar a una cultura misógina o racista.

¿Por qué estos tres aspectos de la libertad son los temas más relevantes actualmente dentro de la política o la filosofía? Los grupos políticos más importantes dentro de la política se pueden dividir en una izquierda que siempre defenderá las libertades políticas de los ciudadanos, no obstante y contario a su filosofía política, la misma izquierda buscará una economía no libre, sino asistencial para sus ciudadanos, buscando por medio de los impuestos generar la mayor cantidad de servicios sociales pero, limitando la libertad económica al restringir el mercado o el comercio con estos mismos impuestos, siendo sólo un ejemplo de otro tipo de restricciones posibles que pueden generarse en este tipo de sistemas económicos. Por otro lado, la derecha que niegan las libertades políticas del ciudadano siempre se encuentra en apoyo de un libre mercado. Por lo tanto, se podría hablar políticamente, sobre la existencia de Estados mixtos, donde se defiende la libertad política más no la económica, o viceversa, pero nunca se defiende una libertad en ambos sectores sociales.

Actualmente, existen grupos indígenas que se gobiernan de forma autónoma basados en sistemas similares a la democracia participativa, pues todos los integrantes de estas comunidades realizan reuniones periódicas en las cuales, los mismos miembros deciden qué leyes deben ser pactadas para el bienestar común. El problema surgiría al saber si ese tipo de socialización es posible en una nación completa, donde serían millones de sujetos quienes buscarían decidir su propia legislación. Otro problema sería, sino es posible una decisión general y, por tanto, se opta por tomar en cuenta la decisión mayoritaria, cómo evitar que esta decisión mayoritaria recaiga en la llamada "dictadura de la mayoría".

El tema de la libertad política ha dado grandes avances al lograr pasar de un sistema de gobierno absolutista a uno democrático, cuando anteriormente no se creía que otra forma de gobierno fuera posible. Sin embargo, el pensamiento clásico del liberalismo ha mostrado tener ciertas fracturas, dando por sentado la necesidad de buscar mejores alternativas liberales. Así 
surgen estos pensadores progresistas, pensadores que lamentablemente tampoco han mostrado ser infalibles, razón por la cual, la idea de libertad sigue y seguirá siendo discutida siempre en un sentido de progreso, estando en un constante devenir intentando conseguir el mayor grado de libertad humana que sea posible de adquirir, pues queda en claro que la libertad absoluta no es posible, ya que, de existir, siempre habría quien trataría de abusar de ella para reprimir la libertad de alguien más. Pero no por ello, los pensadores se han limitado a una sola idea de libertad y siempre continúan en su búsqueda hacia la utopía.

\section{Referencias}

Agustín, S. (2007). La Ciudad de Dios (Tr. Santos Santamarta del Río y Miguel Fuentes Lanero). Madrid: Tecnos.

Aristóteles. (Versión de 1988). Política (Tr. Manuel García Valdés). Madrid: Gredos.

Bentham, J. (1839). Compendio de los Tratado de Legislación Civil y Penal. Madrid: Librería De La Viuda Calleja e Hijos.

Dube, S. (2009). Modernidad. (Tr. Jorge Andrade). En Szurmuk, M. e Irwin, R. M. (Coords.), Diccionario de Estudios Culturales Latinoamericanos (pp. 177-182). México: Siglo XXI.

Hayek, F. (1960). The Constitution of Liberty. Chicago: The University Chicago Press.

Hayek, F. A. (1948). Individualism and Economic Order. Chicago: The University Chicago Press.

Kant, I. (2014). Hacia la Paz Perpetua. (Tr. Jacobo Muñoz). En, Kant II. (pp. 299-248). Madrid: Gredos.

Locke, J. (2004). Segundo Tratado Sobre el Gobierno Civil. Un Ensayo Acerca del Verdadero Origen, Alcance y Fin del Gobierno Civil (Tr. Carlos Mellizo). Madrid: Alianza Editorial.

Matteucci, N. (2015). Contractualismo (Tr. Raúl Crisafio, Alfonso García, Miguel Martí, Mariano Martín y Jorge Tula). En Bobbio, N., Matteucci, N. y Pasquino, G. (Dirs.), Diccionario de Política (pp. 351-365). México: Siglo XXI.

Mill, J. (2014). El Utilitarismo (Tr. Esperanza Guisán). Madrid: Alianza. 
Rachels, J. (2006). Introducción a la Filosofía Moral (Tr. Gustavo Ortiz Millán). México: Fondo de Cultura Económica.

Rousseau, J. (1983). Discurso Sobre el Origen de la Desigualdad Entre los Hombres (Tr. Ágnel Pumarega). Recuperado el 19 de septiembre de 2020 desde: https://www.marxists.org/espanol/rousseau/disc.pdf

Rousseau, J. (2014). El Contrato Social (Tr. Consuelo Bergés). En, Rousseau (pp. 255-370). Madrid: Gredos.

Smith, A. (1978). Teoría de los Sentimientos Morales (Tr. Edmundo O’Gorman). México: Editorial Fondo de Cultura Económica.

Smith, A. (1995). La Riqueza de las Naciones (Tr. Carlos Rodríguez Braun). Madrid: Alianza editorial, colección el libro de bolsillo.

Taylor, C. (1994). La Ética de la Autenticidad (Tr. Pablo Carbajosa Pérez). Barcelona: Paidós.

Taylor, C. (1997). Argumentos Filosóficos (Tr. Fina Birulés Bertrán). Barcelona: Paidós.

Taylor, C. (2009). El Multiculturalismo y "la Política del Reconocimiento" (Tr. Mónica Utrilla De Neira, Liliana Andrade Lianas y Gerard Vilar Roca). México: Fondo de Cultura Económica.

Tocqueville, A. (1984). La Democracia en América Tomos I y II (Tr. Cedida por Alianza Editorial). Madrid: Editorial Sarpe de la colección los grandes pensadores.

Walzer, M. (1997). Las Esferas de la Justicia. Una Defensa del Pluralismo y la Igualdad. México: Fondo de Cultura Económica.

Walzer, M. (2004). Razón, Política y Pasión. 3 defectos del Liberalismo. Conferencia presentada en Conferencias Max Horkheimer. Fráncfort del Meno en 1999. Madrid: La balsa de la medusa. Weber, M. (2005). Conceptos Sociológicos Fundamentales (Tr. Joaquín Abellán). Madrid: Alianza. 